\title{
Reduced expression of miR-205-5p promotes apoptosis and inhibits proliferation and invasion in lung cancer $A 549$ cells by upregulation of ZEB2 and downregulation of erbB3
}

\author{
MIN JIANG ${ }^{1}$, TING ZHONG ${ }^{2}$, WEI ZHANG ${ }^{3}$, ZUKE XIAO $^{1}$, GUOZHU HU $^{1}$, HONG ZHOU $^{1}$ and HAIBIN KUANG ${ }^{2}$ \\ ${ }^{1}$ Department of Respiration, Jiangxi Province People's Hospital; ${ }^{2}$ Department of Physiology, School of Medicine, \\ Nanchang University; ${ }^{3}$ Department of Respiration, The First Affiliated Hospital of \\ Nanchang University, Nanchang, Jiangxi 330006, P.R. China \\ Received February 6, 2016; Accepted February 9, 2017
}

DOI: $10.3892 / \mathrm{mmr} .2017 .6398$

\begin{abstract}
Previous studies have demonstrated that microRNA (miR)-205-5p expression is significantly increased in non-small cell lung cancer tissues and is associated with tumor differentiation grade. The aim of the present study was to explore the effects of miR-205-5p on viability, apoptosis and invasion of lung cancer A549 cells. The hsa-miR-205-5p small interfering RNA (siRNA) inhibitor was transfected into A549 cells and expression of miR-205-5p was detected by reverse transcription-quantitative polymerase chain reaction (RT-qPCR). Cell viability, apoptosis and invasion were assayed by Cell Counting kit-8, Annexin V/propidium iodide double staining and Transwell assay, respectively. Target genes of miR-205-5p were predicted using bioinformatics analysis. Expression of mRNA and protein levels of candidate target genes following miR-205-5p inhibition were detected using RT-qPCR and western blot analysis respectively. The results demonstrated that relative survival rates of A549 cells were significantly inhibited in miR-205-5p siRNA-transfected cells at 24 and $48 \mathrm{~h}$ compared with control cells. Apoptosis was markedly increased in the miR-205-5p siRNA cells compared with control cells. The number of invaded cells following miR-205-5p siRNA silencing was significantly decreased compared with control cells. Bioinformatics analysis revealed that erb-B2 receptor kinase 3 (erbB3), zinc finger E-box binding homeobox 2 (ZEB2),
\end{abstract}

Correspondence to: Dr Haibin Kuang, Department of Physiology, School of Medicine, Nanchang University, 461 Bayi Road, Nanchang, Jiangxi 330006, P.R. China

E-mail: kuanghaibin@ncu.edu.cn

Dr Wei Zhang, Department of Respiration, The First Affiliated Hospital of Nanchang University, 17 Yongwai Street, Nanchang, Jiangxi 330006, P.R. China

E-mail: zhangweiliuxin@163.com

Key words: microRNA-205-5p, A549 cells, proliferation, apoptosis, invasion, non-small cell lung cancer clathrin heavy chain (CLTC) and mediator complex subunit 1 (MED1) may be potential target genes of miR-205-5p. Reduced expression of miR-205-5p significantly increased the expression of ZEB2 mRNA and protein, inhibited the expression of erbB3 protein, but had no significant effect on the expression levels of CLTC and MED1. In summary, reduced expression of miR-205-5p promoted apoptosis and inhibited proliferation and invasion in lung cancer A549 cells through upregulation of ZEB2 and downregulation of erbB3. The present results suggested that the increased miR-205-5p expression observed in non-small cell lung cancer tissues may contribute to increased proliferation and invasion of lung cancer cells and thus to cancer progression.

\section{Introduction}

MicroRNAs (miRs) are small (20-25 nucleotides) endogenous regulatory non-coding RNAs present in eukaryotes. Previous studies have revealed an important role for miRNAs in oncogenesis and tumor metabolism (1-3). Expression of specific miRNAs (including miR-15a, miR-16-1, miR-155, miR-17-92, miR-0372, miR-373 and Let-7) has been demonstrated in various tumor tissues, and $\sim 50 \%$ of these miRNAs are positioned in tumor-related fragile sites of the genome (1-4). Therefore, miRNAs are crucial in the occurrence and development of tumors.

Various tumor-associated specific molecular markers, such as miRs, are important in the early diagnosis of cancer and other diseases (5). miR expression in cancer tissues is dysregulated $(2,3,6)$, and their expression pattern exhibits a certain degree of tissue specificity $(7,8)$. miR-205 is a multi-functional gene located in the 1q32.2 locus of the human genome, and is involved in various physiological and pathological processes, including tumorigenesis, inflammation and immunity (8). miR-205 is abnormally expressed in a variety of malignant tumors and its expression is closely related to the incidence and development of tumors, such as head and neck cancer, ovarian cancer and breast cancer (8-10). Previously, Lebanony et al (11) and the authors (12) both reported that miR-205 expression is significantly increased in non-small cell lung cancer (NSCLC) tissues, and that it is associated 
with tumor differentiation grade (12). However, the function of miR-205-5p in lung cancer remains poorly understood.

In the present study, the aim was to explore the effects of miR-205-5p on proliferation, apoptosis, and invasion of A549 lung cancer cells. The results of the present study may provide important information about the role of miR-205-5p in the biological functions of lung cancer cells and might provide new potential targets for lung cancer treatment.

\section{Materials and methods}

Cell culture and transfection. A549 human lung carcinoma cells were cultured in RPMI-1640 medium (Thermo Fisher Scientific, Inc., Waltham, MA, USA) containing 10\% fetal bovine serum (FBS; Thermo Fisher Scientific, Inc.), $100 \mathrm{IU} / \mathrm{ml}$ penicillin, and $1 \mu \mathrm{g} / \mathrm{ml}$ streptomycin in $5 \% \mathrm{CO}_{2}$ at $37^{\circ} \mathrm{C}$. Cells were passaged every 2-3 days. Prior to transfection, cells were seeded in $24-$ well plates at $1 \times 10^{5}$ cells/well. Cells were cultured until $90 \%$ confluence. hsa-miR-205-5p inhibitor small interfering RNA (5'-AATTCCAGACTCCG GTGGAATGAAGGACGATCAGACTCCGGTGGAATGAAG GAACCGGTCAGACTCCGGTGGAATGAAGGATCACCA GACTCCGGTGGAATGAAGGATTTTTTACCGG-3'; Hibio Technologies Co., Ltd., Hangzhou, China) or miRNA inhibitor scramble negative control (cat. no. A06001; Shanghai GenePharma Co., Ltd., Shanghai, China) were diluted in $100 \mu 1$ Opti-MEM (Thermo Fisher Scientific, Inc.) and mixed with $1 \mu$ l Lipofectamine 2000 (Thermo Fisher Scientific, Inc.) diluted in $100 \mu \mathrm{l}$ Opti-MEM. The transfection solution (200 $\mu \mathrm{l} /$ well) was added to the 24 -well plate. Following 4-6 h, the solution was replaced by only RPMI-1640 medium.

Cell viability. The cells were divided into three groups: control check group (CK; untransfected cells), negative control group (NC; cells transfected with scramble negative control siRNA) and hsa-miR-205-5p siRNA group (siRNA; cells transfected with has-miR-205-5p inhibitor siRNA). At one day prior to transfection, A549 cells, in the logarithmic phase of growth, were diluted to $1 \times 10^{4}$ cells/ml with RPMI-1640 complete medium and were seeded into 96 -cell plates (100 $\mu \mathrm{l} /$ well). The cells were cultured at $37^{\circ} \mathrm{C}$ with $5 \% \mathrm{CO}_{2}$ to obtain a confluence of $\sim 30 \%$ at $24 \mathrm{~h}$. The cells were then transfected as described above and cultured for an additional $72 \mathrm{~h}$. At 24, 48 and $72 \mathrm{~h}$ post-transfection, $10 \mu \mathrm{l}$ Cell Counting kit-8 solution (Dojindo Molecular Technologies, Inc., Kumamoto, Japan) was added to each well, and the culture was continued for $1 \mathrm{~h}$. Absorbance was then measured in a ELx800 spectrophotometer (BioTek Instruments, Inc., Winooski, VT, USA) at $450 \mathrm{~nm}$. Cell survival rate (\%) was calculated as follows: (OD of each experimental group/OD of the CK group) $\mathrm{x} 100$.

Apoptosis. Following transfection for 24, 48 and 72 h, cells were dissociated using EDTA-free trypsin, centrifuged at $252 \times \mathrm{g} \mathrm{rpm}$ for $5 \mathrm{~min}$ at $4^{\circ} \mathrm{C}$, and the medium was discarded. Cells were rinsed twice with cooled PBS and suspended in $400 \mu 11 \mathrm{x}$ binding buffer, as per the kit's instructions (Alexa Fluor 488 Annexin V/Dead Cell Apoptosis kit; Thermo Fisher Scientific, Inc.). Annexin V-Alexa Fluor $488(5 \mu 1)$ and propidium iodide $(1 \mu \mathrm{l})$ were then added and cells were analyzed using a BD FACSVerse flow cytometer (BD
Biosciences) and BD FACSuite software (version 1.0.0.1477; BD Biosciences, Franklin Lakes, NJ, USA).

Cell invasion assay. Matrigel was liquefied at $4^{\circ} \mathrm{C}$ and diluted with cooled serum-free RPMI-1640 medium. Then, $100 \mu 1$ diluted gel was added to the upper chamber of a 24-well Transwell plate, and incubated at $37^{\circ} \mathrm{C}$ overnight in order to solidify. Following incubation, the gel was gently washed with serum-free RPMI-1640 medium. Cells were dissociated following transfection for 24,48 and $72 \mathrm{~h}$, and diluted to $1 \times 10^{5}$ cells $/ \mathrm{ml}$ in $1 \% \mathrm{FBS} / \mathrm{RPMI}-1640$. The cells (200 $\left.\mu \mathrm{l}\right)$ were then added to the upper chamber of the Transwell and 10\% FBS/RPMI-1640 medium was added to the lower chamber as a chemoattractant. Following $24 \mathrm{~h}$, the non-invaded cells on the upper side of the chamber filters were removed with cotton swabs, and filters were air-dried. Finally, filters were stained with $0.1 \%$ crystal violet. Invaded cells were calculated as cells/field by imaging four random fields (magnification, x200).

RNA extraction and reverse transcription-quantitative polymerase chain reaction (RT-PCR). Total RNA was extracted using TRIzol (Thermo Fisher Scientific, Inc.), according to the manufacturer's instructions. Purity was determined using the A260/A280 and A260/A230 ratios. RNA quality with A260/A280 of 1.8-2.0 was determined adequate for RT-qPCR. Reverse transcription was performed using $10 \mu \mathrm{l}$ total RNA, $4 \mu \mathrm{l}$ $5 \mathrm{X}$ reaction buffer, $1 \mu \mathrm{l}$ RiboLock RNase inhibitor (Thermo Fisher Scientific, Inc.), $2 \mu 110 \mathrm{mM}$ dNTP, $1 \mu 1$ RevertAid reverse transcriptase (Thermo Fisher Scientific, Inc.), and $1 \mu 110 \mu \mathrm{M}$ primers. cDNA was stored at $-70^{\circ} \mathrm{C}$. RT-qPCR was performed using 12.5 $\mu \mathrm{l}$ iQ SYBR-Green Supermix (Bio-Rad Laboratories, Inc., Hercules, CA, USA), $1 \mu \mathrm{l} 10 \mu \mathrm{M}$ primers, and $10.5 \mu \mathrm{l}$ cDNA in a Real-time PCR ABI Prism 7500 system (Applied Biosystems; Thermo Fisher Scientific, Inc.). PCR parameters were: $50^{\circ} \mathrm{C}$ for $3 \mathrm{~min}$ and $95^{\circ} \mathrm{C}$ for $3 \mathrm{~min}$, followed by 40 cycles of $95^{\circ} \mathrm{C}$ for $10 \mathrm{sec}, 65^{\circ} \mathrm{C}$ for $20 \mathrm{sec}, 72^{\circ} \mathrm{C}$ for $15 \mathrm{sec}$, and a final step of $76^{\circ} \mathrm{C}$ for $5 \mathrm{sec}$. Primer sequences were: miR-205-5p stem-loop, 5'-GTC GTATCCAGTGCAGGGTCCGAGGTATTCGCACTG GATACGACCGCCAATA-3'; miR-205-5p (accession no. MIMAT0000069; product size $66 \mathrm{bp}$ ), forward 5'-TATCCA GTGCAGGGTCCGAGGTAT-3' and reverse 5'-CGGCGG TAGCAGCACGTAAATAT-3'; RNU6B (internal reference), forward 5'-CTCGCTTCGGCAGCACA-3' and reverse 5'-AACGCTTCACGAATTTGCGT-3'. For erb-B2 receptor kinase 3 (erbB3), zinc finger E-box binding homeobox 2 (ZEB2), clathrin heavy chain (CLTC) and mediator complex subunit 1 (MED1), the following primers were used: GAPDH (internal reference; Genbank ID 2597; product size 258 bp), forward 5'-AGAAGGCTGGGGCTCATTTG-3' and reverse 5'-AGGGGCCATCCACAGTCTTC-3'; erbB-3 (Genbank ID 2065; product size $225 \mathrm{bp}$ ), forward 5'-TGCTGAGAACCA ATACCAGACA-3' and reverse 5'-GCAAACTTCCCATCG TAGACC-3'; ZEB2 (Genbank ID 9839; product size 283 bp), forward 5'-CGTACTCGCAGCACATGAATC-3' and reverse 5'-TCCTCCTCGAACTCCTCGTC-3'; CLTC (Genbank ID 1213; product size $111 \mathrm{bp}$ ), forward 5'-TCCAGAACCTGG GTATCAACC-3' and reverse 5'-TTACCACCTGGGCCT GCTC-3'; and MED1 (Genbank ID 5469; product size 123 bp), forward 5'-GTGGCTCTTCCATGTCATCCT-3' and reverse 5'-TGGTGACAACCCCATGCTTC-3'. 


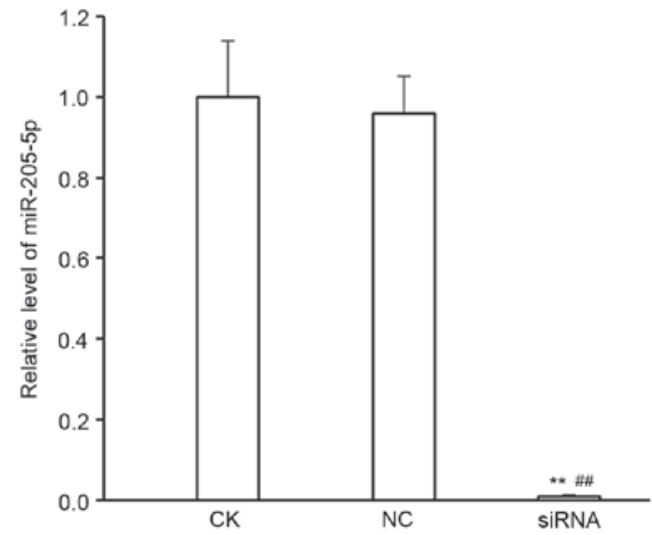

Figure 1. Expression of miR-205-5p mRNA in A549 cells transfected with hsa-miR-205-5P siRNA. A549 cells were either untransfected (CK), or transfected with negative control scramble siRNA (NC) or the hsa-miR-205-5P specific siRNA. mRNA expression levels were then determined by reverse transcription-quantitative polymerase chain reaction. Each experiment was performed 3 times. ${ }^{* *} \mathrm{P}<0.01$ vs. $\mathrm{CK}$ group; ${ }^{\#} \mathrm{P}<0.01$ vs. NC group. $\mathrm{CK}$, control check group; NC, scramble negative control group; siRNA, miR-205-5p siRNA group.

Prediction of hsa-miR-205-5p target genes. The hsa-miR-205-5 sequences were acquired from miRBase (http://www.mirbase.org; hsa-miR-205-5p; MIMAT0000 266) (13). The hsa-miR-205-5p target genes were predicted using three network platforms: TargetScan (http://www.targetscan. org/vert_61/) (14), 416 loci of conservative target sequences; PicTar (http://pictar.mdc-berlin.de/) (15), 274 loci of conservative target sequences; and miRDB (http://mirdb.org/miRDB/) (16), 421 loci of conservative target sequences.

Using miRDB and TargetScan2, there were 157 common sequences. Using TargetScan 2 and PicTar, there were 70 common sequences. Using TargetScan2, PicTar, and miRDB, there were 33 common sequences. The predicted target genes were analyzed using the Gene Ontology Consortium (17-18) and Mas 3.0 Molecule Annotation System (http://bioinfo. capitalbio.com/mas3/) (18). Finally, 16 genes were analyzed, and the miRDB and TargetScan 2 common sequences were considered as references.

Western blot analysis. Cells were dissociated with trypsin and centrifuged at $600 \times \mathrm{g}$ at $4^{\circ} \mathrm{C}$ for $5 \mathrm{~min}$. Cells were resuspended in PBS and centrifuged a second time. RIPA lysis buffer (Applygen Technologies, Inc., Beijing, China) was then added. Following lysis, samples were centrifuged at $16,099 \times \mathrm{g}$ at $4^{\circ} \mathrm{C}$ for $10 \mathrm{~min}$. The supernatant was transferred to a new centrifuge tube and stored at $-70^{\circ} \mathrm{C}$. Protein concentration was determined using the bicinchoninic acid assay method (Applygen Technologies, Inc.). Protein samples $(20 \mu \mathrm{g})$ were diluted with sample buffer and denatured at $95^{\circ} \mathrm{C}$ for $5 \mathrm{~min}$. Proteins were separated using 10\% SDS-PAGE at $25 \mathrm{~mA}$ for $30 \mathrm{~min}$ and then at $30 \mathrm{~mA}$ for $2 \mathrm{~h}$. Proteins were transferred to a polyvinylidene fluoride membrane at $200 \mathrm{~mA}$ overnight. Membranes were blocked with 5\% non-fat milk or bovine serum albumin at room temperature overnight. The membranes were incubated at room temperature for $2 \mathrm{~h}$ with the following primary antibodies: TRAP220/MED1 (1:1,000 dilution; cat. no. ab64695; Abcam, Cambridge, MA, USA), Smad Interacting Protein 1 (1:2,000 dilution; cat. no. ab25837;

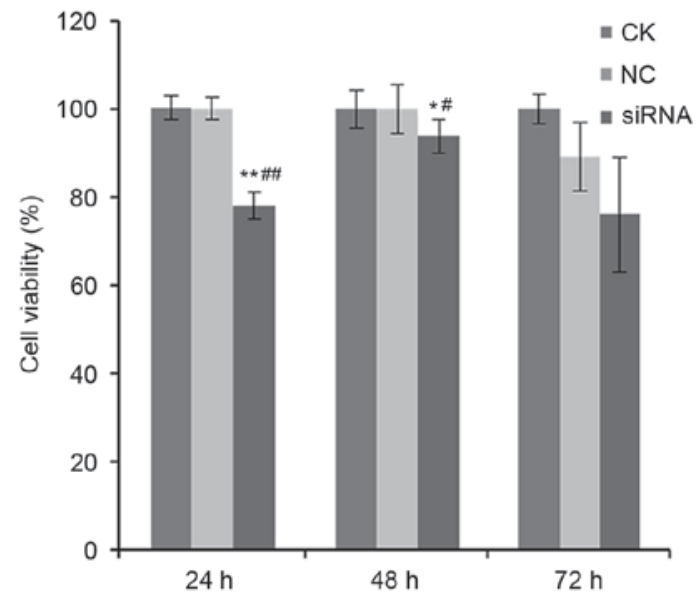

Figure 2. Effect of miR-205-5p silencing on cell viability. Cell viability in A549 cells was measured at 24,48 and $72 \mathrm{~h}$ following transfection with hsa-miR-205-5P siRNA. Each experiment was performed 3 times. " $\mathrm{P}<0.05$ and ${ }^{* *} \mathrm{P}<0.01$ vs. CK group; ${ }^{\#} \mathrm{P}<0.05$ and ${ }^{\# \#} \mathrm{P}<0.01$ vs. NC group. siRNA, small interfering RNA; CK, control check group; NC, scramble negative control group; siRNA, miR-205-5p siRNA group.

Abcam), HER3/ErbB3 (1:1,000 dilution; cat. no. 4754S; Cell Signaling Technology, Inc., Danvers, MA, USA), clathrin heavy chain (P1663) antibody (1:2,000 dilution; 2410S; Cell Signaling Technology, Inc.) and $\beta$-actin (1:1,000 dilution; cat. no. SC-47778; Santa Cruz Biotechnology, Inc., Dallas, TX, USA). The membranes were rinsed thrice for $15 \mathrm{~min}$ each time. Membranes were incubated with the secondary antibody (goat anti-rabbit immunoglobulin G-horseradish peroxidase; 1:5,000 dilution; cat. no. BS13278; Bioworld Technology Inc., Louis Park, MN, USA) for $45 \mathrm{~min}$ at room temperature and rinsed thrice. Membranes were developed using an enhanced chemiluminescence kit (Pierce; Thermo Fisher Scientific, Inc.). The relative band intensity was acquired using the Quantity One software version 4.4 (Bio-Rad Laboratories, Inc.).

Statistical analysis. Statistical analysis was performed using SPSS software (version, 12.0; SPSS. Inc., Chicago, IL, USA). Data were expressed as mean \pm standard deviation and analyzed using analysis of variance with Tukey's post-hoc test. $\mathrm{P}<0.05$ was considered to indicate a statistically significant difference.

\section{Results}

miR-205-5P siRNA silencing in A549 cells. Firstly, the efficiency of silencing miR-205-5p expression by siRNA transfection was validated. There were no differences in miR-205-5p expression levels between the CK and NC groups ( $\mathrm{P}>0.05$ ), while miR-205-5p expression levels were significantly reduced in the miR-205-5p siRNA group compared with the $\mathrm{CK}$ and $\mathrm{NC}$ group $(\mathrm{P}<0.01 ;$ Fig. 1$)$.

Effect of miR-205-5p silencing on cell viability. Next, the effect of silencing miR-205-5p expression on cell viability was assessed in A549 cells. The relative survival rates at 24, 48 and $72 \mathrm{~h}$ post-siRNA transfection in the NC group were $100.0 \pm 2.6,100.0 \pm 5.6$ and $89.2 \pm 7.7 \%$, respectively, while those in the miR-205-5p siRNA group were 78.1 $\pm 3.0,93.9 \pm 3.8$ and 

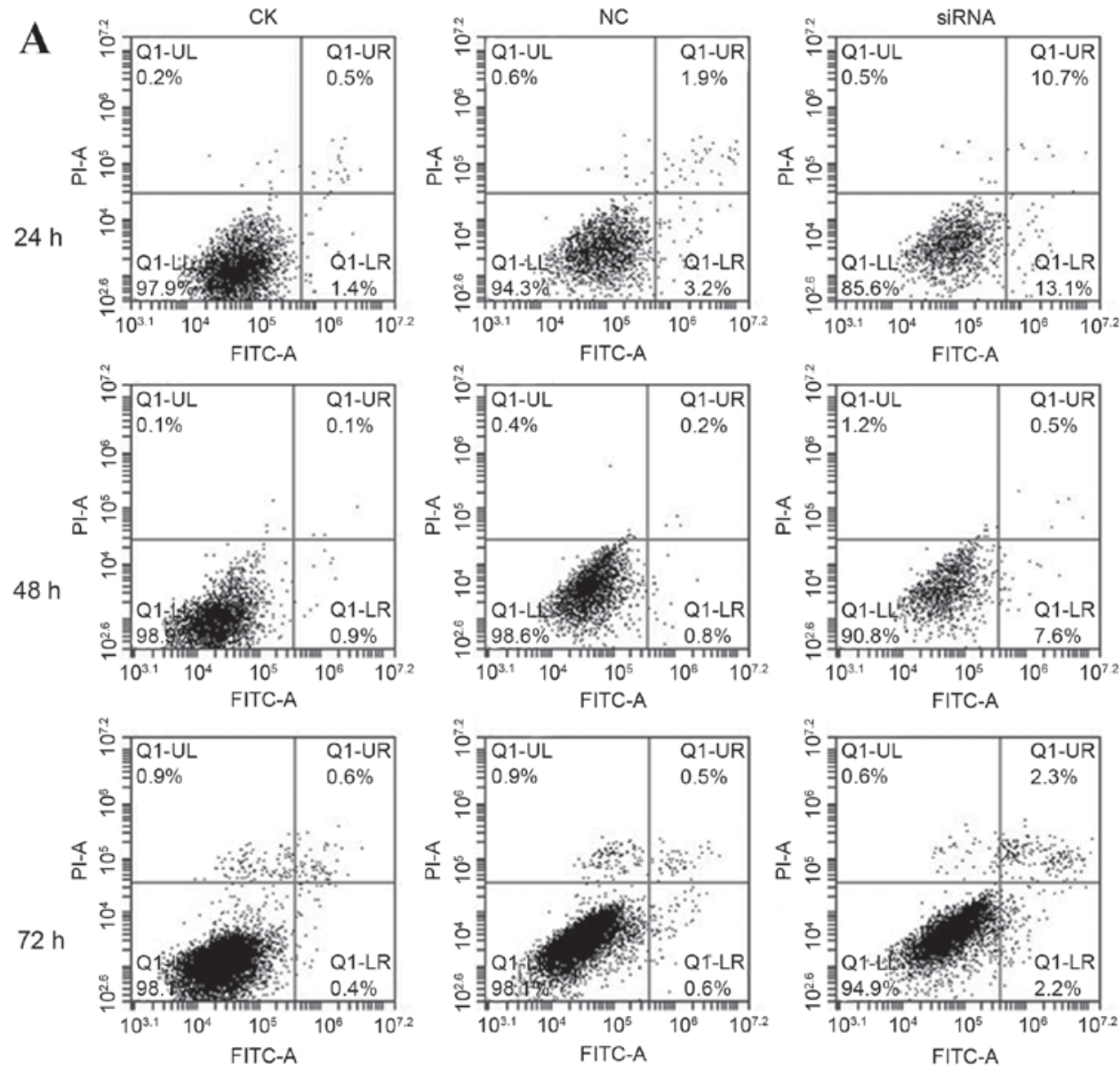

B

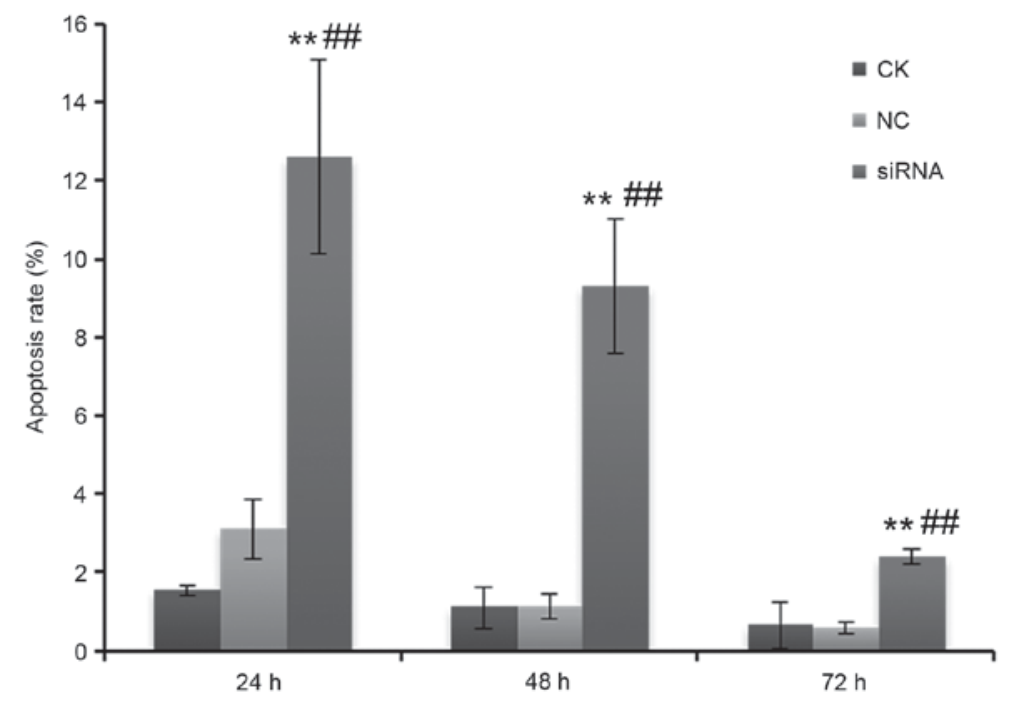

Figure 3. Effect of miR-205-5p silencing on cell apoptosis. Apoptosis was measured in A549 cells following transfection with hsa-miR-205-5P siRNA by Annexin V/PI double staining and flow cytometry analysis. (A) Representative flow cytometry plots of A549 cells at 24, 48 and $72 \mathrm{~h}$ post-transfection. (B) Quantification of flow cytometry results, presented as mean \% of apoptotic cells in the total cell population \pm standard deviation. Each experiment was performed 3 times. ${ }^{* *} \mathrm{P}<0.01$ vs. CK group; ${ }^{* \#} \mathrm{P}<0.01$ vs. NC group. siRNA, small interfering RNA; FITC, fluorescein isothiocyanate; PI, propidium iodide; CK, control check group; NC, scramble negative control group; siRNA, miR-205-5p siRNA group.

$76.0 \pm 13.0 \%$, respectively $(\mathrm{P}<0.01$ for $24 \mathrm{~h}$ and $\mathrm{P}<0.05$ for 48 h; Fig. 2). However, there were no significant differences between the $\mathrm{NC}$ and $\mathrm{CK}$ groups, suggesting that the negative control scramble siRNA had no effect on cell viability (P>0.05; Fig. 2).
Effect of miR-2015-5p silencing on apoptosis. The effect of silencing miR-205-5p expression was then examined on cell apoptosis in A549 cells. At 24, 48 and $72 \mathrm{~h}$ following transfection with miR-205-5p siRNA, the \% of apoptotic cells in the total cell population in the miR-205-5p siRNA group were 
Table I. miR-205-5p candidate target genes.

\begin{tabular}{lclll}
\hline Target rank & Target score & miRNA name & Gene symbol & \\
\hline 260 & 59 & hsa-miR-205-5p & SBF2 & SET binding factor 2 \\
17 & 90 & hsa-miR-205-5p & RAB11FIP1 & RAB11 family interacting protein 1 (class I) \\
70 & 79 & hsa-miR-205-5p & ERBB3 & Erb-b2 receptor tyrosine kinase 3 \\
28 & 86 & hsa-miR-205-5p & PLCB1 & Phospholipase C, beta 1 \\
404 & 51 & hsa-miR-205-5p & PHC2 & Polyhomeotic homolog 2 \\
4 & 98 & hsa-miR-205-5p & MED1 & Mediator complex subunit 1 \\
37 & 84 & hsa-miR-205-5p & LRP1 & Low density lipoprotein receptor-related protein 1 \\
278 & 58 & hsa-miR-205-5p & LAMC1 & Laminin subunit gamma 1 \\
26 & 86 & hsa-miR-205-5p & KLF12 & Kruppel-like factor 12 \\
19 & 89 & hsa-miR-205-5p & ZEB2 & Zinc finger E-box binding homeobox 2 \\
169 & 66 & hsa-miR-205-5p & HS3ST1 & Heparan sulfate-glucosamine 3-O-sulfotransferase 1 \\
202 & 64 & hsa-miR-205-5p & FRK & Fyn-related kinase \\
87 & 75 & hsa-miR-205-5p & CLTC & Clathrin heavy chain \\
64 & 79 & hsa-miR-205-5p & BTBD3 & BTB domain containing 3 \\
307 & 56 & hsa-miR-205-5p & ADAMTS9 & ADAM metallopeptidase with thrombospondin type 1 motif 9 \\
21 & 88 & hsa-miR-205-5p & ACSL1 & Acyl-CoA synthetase long-chain family member 1 \\
\hline
\end{tabular}

miR, microRNA; SET, Suvar3-9, Enhancer-of-zeste, Trithorax; RAB11, Ras-related protein Rab-11; BTB, BR-c, ttk and bab; ADAM, a disintegrin and mettaloproteinase.
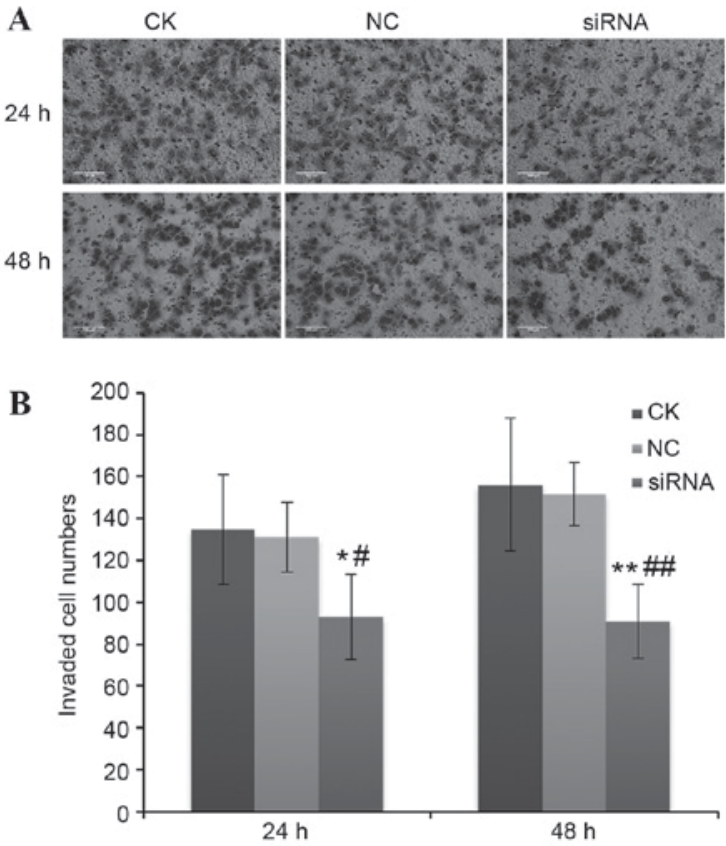

Figure 4. Effect of miR-205-5p silencing on cell invasion. Cell invasion was assessed in A549 cells at $24 \mathrm{~h}$ and $48 \mathrm{~h}$ following transfection with hsa-miR-205-5p siRNA by invasion Transwell chambers. (A) Representative microscope images of invaded A549 cells. (B) Quantification of invaded A549 cells. Each experiment was performed 3 times. ${ }^{*} \mathrm{P}<0.05$ and ${ }^{* *} \mathrm{P}<0.01$ vs. CK group; ${ }^{\#} \mathrm{P}<0.05$ and ${ }^{\# \#} \mathrm{P}<0.01$ vs. $\mathrm{NC}$ group. siRNA, small interfering RNA; CK, control check group; NC, scramble negative control group; siRNA, miR-205-5p siRNA group.

$12.6 \pm 2.5,9.3 \pm 1.7$ and $2.4 \pm 0.2 \%$, respectively, while in the $\mathrm{NC}$ group, these were $3.1 \pm 0.8,1.1 \pm 0.3$, and $0.6 \pm 0.2 \%$, respectively $(\mathrm{P}<0.01$; Fig. 3$)$.
Effect of miR-2015-5p silencing on cell invasion. The effect of silencing miR-205-5p expression on cell invasion of A549 cells was examined. The average number of invaded cells per field at 24 and $48 \mathrm{~h}$ following transfection with miR-205-5p siRNA were $93 \pm 20$ and $91 \pm 18$ in miR-205-5p siRNA group, respectively, while those in the NC group were $131 \pm 17$ and $135 \pm 26$, respectively ( $\mathrm{P}<0.05$; Fig. 4$)$.

Prediction of miR-205-5p target genes by bioinformatics analysis. In order to explore the pathways involved in the effects of miR-205-5p, the potential target genes of miR-205-5p were predicted by bioinformatics analysis, using miRDB, TargetScan and PicTar web-based software (data not shown). Bioinformatics analysis revealed 16 candidate miR-205-5p target genes (Table I). Based on to the annotated functions for these genes, erbB3 (involved in cell proliferation), ZEB2 (promoter of metastasis), CLTC (promoter of tumor growth and angiogenesis) and MED1 (involved in proliferation, differentiation and metabolism) were speculated to be the major potential target genes of miR-205-5p.

Effect of miR-205-5p silencing on mRNA expression of erbB3, ZEB2, CLTC, and MED1 in A549 cells. In order to confirm that the predicted target genes were indeed regulated by miR-205-5p, the mRNA expression levels of erbB3, ZEB2, CTLC and MED1 were assessed in A549 cells using RT-qPCR following miR-205-5p silencing. The results demonstrated that erbB3 mRNA expression in NC and miR-205-5p siRNA groups was $0.594 \pm 0.185$ and $0.831 \pm 0.269$, respectively (P>0.05; Fig. 5). ZEB2 mRNA expression in the $\mathrm{NC}$ and siRNA groups was $0.616 \pm 0.046$ and $1.337 \pm 0.372$, respectively $(\mathrm{P}<0.05$; Fig. 5). CLTC mRNA expression in the NC and siRNA groups was $0.421 \pm 0.117$ and $0.470 \pm 0.105$, respectively (P>0.05; Fig. 5). MED1 mRNA expression in the NC and 


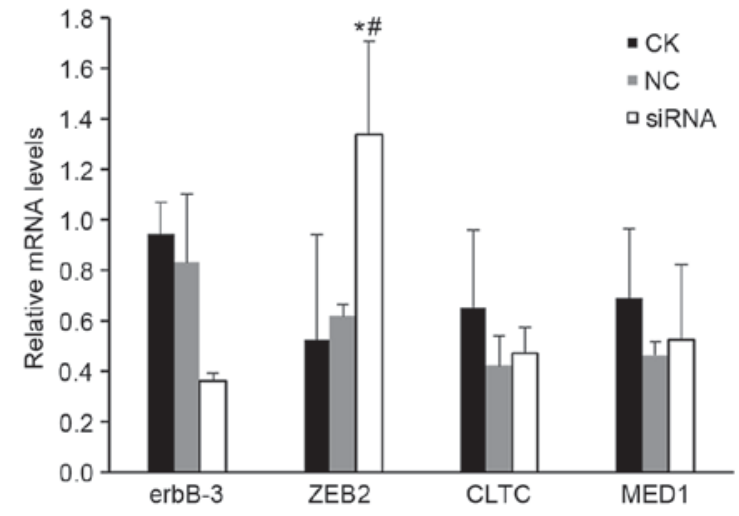

Figure 5. Effect of miR-205-5p silencing on mRNA expression of predicted target genes. The mRNA expression levels of predicted target genes erbB3, ZEB2, CLTC and MED1 were assessed in A549 cells following transfection with hsa-miR-205-5p siRNA by reverse transcription-quantitative polymerase chain reaction. Each experiment was performed 3 times. ${ }^{*} \mathrm{P}<0.05$ vs. CK group; ${ }^{~} \mathrm{P}<0.05$ vs. NC group. erbB3, Erb-B2 receptor kinase 3; ZEB2, zinc finger E-box binding homeobox 2; CLTC, clathrin heavy chain; MED1, mediator complex subunit 1; siRNA, small interfering RNA; CK, control check group; NC, scramble negative control group; siRNA, miR-205-5p siRNA group.
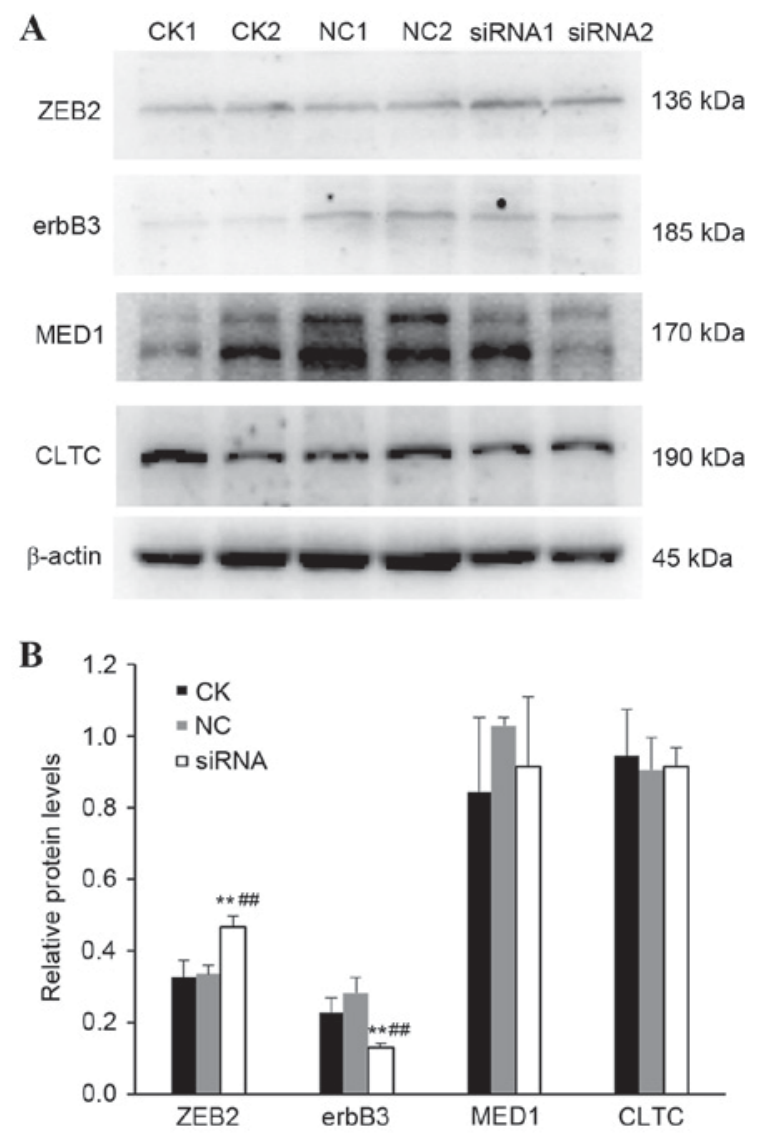

Figure 6. Effect of miR-205-5p silencing on protein expression of predicted target genes. The protein expression levels of target genes erbB3, ZEB2, CLTC and MED1 were assessed in A549 cells following transfection with hsa-miR-205-5p siRNA, by western blotting. (A) Representative immunoblotting results from a duplicate experiment. (B) Densitometric analysis and quantification from three independent experiments. Each experiment was performed 3 times. ${ }^{* *} \mathrm{P}<0.01$ vs. $\mathrm{CK}$ group; ${ }^{* \#} \mathrm{P}<0.01$ vs. NC group. erbB3, Erb-B2 receptor kinase 3; ZEB2, zinc finger E-box binding homeobox 2; CLTC, clathrin heavy chain; MED1, mediator complex subunit 1; siRNA, small interfering RNA; CK, control check group; NC, scramble negative control group; siRNA, miR-205-5p siRNA group.
siRNA groups was $0.461 \pm 0.052$ and $0.524 \pm 0.298$, respectively ( $\mathrm{P}>0.05$; Fig. 5). Therefore, out of the four genes tested, only ZEB2 exhibited a significant increase in mRNA expression following miR-205-5p silencing (Fig. 5).

Effect of miR-205-5p silencing on protein expression of erbB3, ZEB2, CLTC and MED1 in A549 cells. In order to confirm the results obtained for the mRNA expression levels, protein expression levels were also examined by western blotting (Fig. 6). The results demonstrated that erbB3 protein expression in the $\mathrm{NC}$ and siRNA groups was $0.283 \pm 0.042$ and $0.130 \pm 0.009$, respectively ( $\mathrm{P}<0.01$; Fig. 6). ZEB2 protein expression in the $\mathrm{NC}$ and siRNA groups was $0.335 \pm 0.025$ and $0.465 \pm 0.031$, respectively $(\mathrm{P}<0.01$; Fig. 6). CLTC and MED1 protein expressions in the $\mathrm{NC}$ and siRNA groups were $0.905 \pm 0.090$ and $0.914 \pm 0.052$, and $1.029 \pm 0.025$ and $0.913 \pm 0.198$, respectively ( $\mathrm{P}>0.05$; Fig. 6). Therefore, miR-205-5p silencing resulted in a significant decrease of erbB3 and a significant increase of ZEB2 protein expression levels compared with control cells (Fig. 6).

\section{Discussion}

The aim of present study was to explore the effects of miR-205-5p on viability, apoptosis and invasion of lung cancer A549 cells. Results demonstrated that cell viability and cell invasion were significantly decreased, while apoptosis was significantly increased in miR-205-5p siRNA group compared with the control group. Bioinformatics analysis speculated that erbB3, ZEB2, CLTC and MED1 may be potential target genes of miR-205-5p. Reduced expression of miR-205-5p significantly increased the expression levels of ZEB2 mRNA and protein, while it decreased the expression of erbB3 protein, suggesting that ZEB2 and erbB3 are indeed target genes of miR-205-5p in A549 cells. No significant effect was observed on the expression of CLTC and MED1 following miR-205-5p silencing.

Proliferation, abnormal apoptosis, invasion and metastasis are important features of malignant tumors, and metastasis is the primary cause of death in cancer patients $(19,20)$. In the present study, miR205-5p silencing led to decreased A549 cell invasion, suggesting that knocking down expression of miR-205-5p in A549 cells may reduce the invasive properties of tumor cells. Similar results were previously observed in breast cancer cells following miR-205-5p silencing (21). TargetScan is a web-based bioinformatics tool used to predict target genes of miRNAs (14). PicTar is a bioinformatics tool mainly focused on identifying target genes containing single miRNA binding sites $(15,22,23)$. Target gene predictions in nematodes using the PicTar software have been confirmed to correspond to several verified miRNA target genes (23). miRDB is a software used for prediction and functional annotation of miRNA targets, which performs target predictions for mature miRNA using a support vector machine algorithm $(16,24)$. Since each prediction software has its limitations, and since there is a lack of high complementarity between miRNAs and their target mRNAs, a miRNA is often associated with hundreds of target genes, leading to a number of false positive predictions (25). Therefore, a cross prediction of miRNA target genes using several prediction programs is likely to greatly improve accuracy. In the present study, prediction of miR-205-5p 
target genes was performed using three different prediction bioinformatics tools: TargetScan2, PicTar and miRDB, and 16 miR-205-5p candidate target genes were identified (SBF2, RAB11FIP1, erbB3, PLCB1, PHC2, MED1, LRP1, LAMC1, KLF12, ZEB2, HS3ST1, FRK, CLTC, BTBD3, ADAMTS9 and ACSL1; Table I). Among these, four genes were selected to be examined further in A549 cells: MED1 as a verified target of miR-205-5p in human trophoblasts (26), erbB3 as a major regulator of cell proliferation (27), ZEB2 as a promoter of metastasis (28) and CLTC as a promoter of tumor growth and angiogenesis (29). RT-qPCR and western blot analyses were used to determine the expression of these four genes at the mRNA and protein level respectively, following transfection with miR-205-5p-targeting siRNA. The results demonstrated that ZEB2 and erbB3 expression were significantly affected by miR-205-5p silencing.

ERBB family members are involved in cell proliferation and differentiation. Members of the ERBB family are dysregulated in breast, lung, ovarian, prostate and gastrointestinal tumors (30). The present study demonstrated that, although silencing miR-205-5p expression in A549 cells did not significantly change the mRNA expression of erbB3, expression of the erbB3 protein levels were significantly reduced compared with control cells. This result indicated that high miR-205-5p expression in NSCLC might enhance the activation of downstream signal pathways through increasing erbB3 expression to promote cell proliferation and malignant transformation.

Epithelial mesenchymal transition (EMT) serves an important role in invasion and metastasis of tumor cells $(31,32)$. E-cadherin maintains the epithelial cell integrity and epithelial cell polarity, and its downregulation is an important feature of EMT. Neural cadherin is another member of the cadherin family, and its upregulation leads to downregulation of E-cadherin and increased cell invasion $(32,33)$. ZEB2 inhibits E-cadherin expression and induces EMT (34). ZEB2 has been confirmed to promote ovarian cancer, breast cancer and gastric cancer cell metastasis, and its upregulation is significantly correlated with poor prognosis in head and neck cancer (35-38). However, there is little information concerning the role of ZEB2 in lung cancer. Oztas et al (39) reported that ZEB2 is not expressed in normal lung tissue, but it is upregulated in up to $70 \%$ of lung cancer tissues. Miura et al (34) observed ZEB2 overexpression in up to $58.4 \%$ of lung cancer tissues. Previous studies have demonstrated that ZEB2 upregulation is negatively correlated with E-cadherin expression and positively correlated with $\mathrm{N}$-cadherin expression in NSCLC, suggesting that ZEB2 may promote EMT in NSCLC $(37,38,40)$. The present study demonstrated that silencing miR-205-5p expression in A549 cells significantly increased mRNA and protein expression of ZEB2, suggesting that miR-205-5p likely regulates expression of ZEB2 through degrading its mRNA. In addition, this result indicated that high miR-205-5p expression may lead to decreased mRNA and protein expression of ZEB2, as previously reported by Liu et al (41) in melanoma cells.

CLTC is involved in the cell cycle and spread of viruses $(42,43)$. CLTC promotes tumor growth and angiogenesis by regulating hypoxia-inducible factor $1-\alpha$ and vascular endothelial growth factor expression (29). CLTC may be associated with lymphoma (44). In the present study, bioinformatics analysis revealed that CLTC may be a potential target gene of miR-205-5p. However, the results did not support that CLTC is a target of miR-205-5p, as its expression was not affected by miR-205-5p silencing. MED1 binds to various nuclear receptors (including peroxisome proliferator-activated receptor- $\alpha$, peroxisome proliferator-activated receptor- $\gamma$ and retinoid $\mathrm{X}$ receptor) and transcription factors (including $\mathrm{p} 53$, GATA and CCAAT/enhancer binding protein $\beta$ ), serving an important regulatory role in proliferation, differentiation and metabolism of cells (45-47). In the present study, bioinformatics analysis predicted that MED1 may be a potential target gene of miR-205-5p, but miR-205-5p silencing did not alter MED1 mRNA or protein expression levels in A549 cells.

In summary, the present study demonstrated that reduced expression of miR-205-5p promoted apoptosis, and inhibited viability and invasion in lung cancer A549 cells through upregulation of ZEB2 and downregulation of erbB3. The present results suggested that increased miR-205-5p expression in NSCLC tissues may promote proliferation and invasion of lung cancer cells and thus disease progression. Further studies are necessary in order to determine the exact role of miR-205-5p in lung cancer and to assess whether it may be a useful target for the development of novel NSCLC treatments.

\section{Acknowledgements}

The study was supported by the Natural Science Foundation of Jiangxi Province (grant no. 20142BAB205012) and the 555 project of Jiangxi Province Gan Po Excellence and Post-Graduate Innovation Project of Nanchang University (grant nos. cx2015176 and cx2016355).

\section{References}

1. Zhang B, Pan X, Cobb GP and Anderson TA: microRNAs as oncogenes and tumor suppressors. Dev Biol 302: 1-12, 2007.

2. Calin GA and Croce CM: MicroRNA signatures in human cancers. Nat Rev Cancer 6: 857-866, 2006.

3. Esquela-Kerscher A and Slack FJ: Oncomirs-microRNAs with a role in cancer. Nat Rev Cancer 6: 259-269, 2006.

4. Zhu XL, Wen SY, Ai ZH, Wang J, Xu YL and Teng YC: Screening for characteristic microRNAs between pre-invasive and invasive stages of cervical cancer. Mol Med Rep 12: 55-62, 2015.

5. Hui A, How C, Ito E and Liu FF: Micro-RNAs as diagnostic or prognostic markers in human epithelial malignancies. BMC Cancer 11: 500, 2011.

6. Lee HY, Han SS, Rhee H, Park JH, Lee JS, Oh YM, Choi SS, Shin SH and Kim WJ: Differential expression of microRNAs and their target genes in non-small-cell lung cancer. Mol Med Rep 11: 2034-2040, 2015.

7. Lu J, Getz G, Miska EA, Alvarez-Saavedra E, Lamb J, Peck D, Sweet-Cordero A, Ebert BL, Mak RH, Ferrando AA, et al: MicroRNA expression profiles classify human cancers. Nature 435: 834-838, 2005.

8. Wu H and Mo YY: Targeting miR-205 in breast cancer. Expert Opin Ther Targets 13: 1439-1448, 2009.

9. Tran N, McLean T, Zhang X, Zhao CJ, Thomson JM, O'Brien C and Rose B: MicroRNA expression profiles in head and neck cancer cell lines. Biochem Biophys Res Commun 358: 12-17, 2007.

10. Iorio MV, Visone R, Di Leva G, Donati V, Petrocca F, Casalini P, Taccioli C, Volinia S, Liu CG, Alder H, et al: MicroRNA signatures in human ovarian cancer. Cancer Res 67: 8699-8707, 2007.

11. Lebanony D, Benjamin H, Gilad S, Ezagouri M, Dov A, Ashkenazi K, Gefen N, Izraeli S, Rechavi G, Pass H, et al: Diagnostic assay based on hsa-miR-205 expression distinguishes squamous from nonsquamous non-small-cell lung carcinoma. J Clin Oncol 27: 2030-2037, 2009. 
12. Jiang M, Zhang P, Hu G, Xiao Z, Xu F, Zhong T, Huang F, Kuang $\mathrm{H}$ and Zhang W: Relative expressions of miR-205-5p, miR-205-3p, and miR-21 in tissues and serum of non-small cell lung cancer patients. Mol Cell Biochem 383: 67-75, 2013.

13. Griffiths-Jones S, Grocock RJ, van Dongen S, Bateman A and Enright AJ: miRBase: MicroRNA sequences, targets and gene nomenclature. Nucleic Acids Res 34 (Database issue): D140-D144, 2006.

14. Lewis BP, Burge CB and Bartel DP: Conserved seed pairing, often flanked by adenosines, indicates that thousands of human genes are microRNA targets. Cell 120: 15-20, 2005.

15. Krek A, Grün D, Poy MN, Wolf R, Rosenberg L, Epstein EJ, MacMenamin P, da Piedade I, Gunsalus KC, Stoffel M and Rajewsky N: Combinatorial microRNA target predictions. Nat Genet 37: 495-500, 2005

16. Wong $\mathrm{N}$ and Wang X: miRDB: An online resource for microRNA target prediction and functional annotations. Nucleic Acids Res 43 (Database issue): D146-D152, 2015.

17. Gene Ontology Consortium: Gene ontology consortium: Going forward. Nucleic Acids Res 43 (Database issue): D1049-D1056, 2015.

18. Ashburner M, Ball CA, Blake JA, Botstein D, Butler H, Cherry JM, Davis AP, Dolinski K, Dwight SS, Eppig JT, et al: Gene ontology: Tool for the unification of biology. The gene ontology consortium. Nat Genet 25: 25-29, 2000.

19. Geiger TR and Peeper DS: Metastasis mechanisms. Biochim Biophys Acta 1796: 293-308, 2009.

20. Hedley BD and Chambers AF: Tumor dormancy and metastasis. Adv Cancer Res 102: 67-101, 2009.

21. Elgamal OA, Park JK, Gusev Y, Azevedo-Pouly AC, Jiang J, Roopra A and Schmittgen TD: Tumor suppressive function of mir-205 in breast cancer is linked to HMGB3 regulation. PLoS One 8: e76402, 2013.

22. Sahoo S and Albrecht AA: Ranking of microRNA target prediction scores by Pareto front analysis. Comput Biol Chem 34: 284-292, 2010

23. Witkos TM, Koscianska E and Krzyzosiak WJ: Practical aspects of microRNA target prediction. Curr Mol Med 11: 93-109, 2011.

24. Wang X: miRDB: A microRNA target prediction and functional annotation database with a wiki interface. RNA 14: 1012-1017, 2008.

25. Hofacker IL: How microRNAs choose their targets. Nat Genet 39: 1191-1192, 2007.

26. Mouillet JF, Chu T, Nelson DM, Mishima T and Sadovsky Y: MiR-205 silences MED1 in hypoxic primary human trophoblasts. FASEB J 24: 2030-2039, 2010.

27. Jullien N, Dieudonné FX, Habel N, Marty C, Modrowski D, Patino A, Lecanda F, Sévère N and Marie PJ: ErbB3 silencing reduces osteosarcoma cell proliferation and tumor growth in vivo. Gene 521: 55-61, 2013.

28. Dai YH, Tang YP, Zhu HY, Lv L, Chu Y, Zhou YQ and Huo JR ZEB2 promotes the metastasis of gastric cancer and modulates epithelial mesenchymal transition of gastric cancer cells. Dig Dis Sci 57: 1253-1260, 2012.

29. Tung KH, Lin CW, Kuo CC, Li LT, Kuo YH, Lin CW and Wu HC: CHC promotes tumor growth and angiogenesis through regulation of HIF-1 $\alpha$ and VEGF signaling. Cancer Lett 331: 58-67, 2013.

30. Yano T, Doi T, Ohtsu A, Boku N, Hashizume K, Nakanishi M and Ochiai A: Comparison of HER2 gene amplification assessed by fluorescence in situ hybridization and HER2 protein expression assessed by immunohistochemistry in gastric cancer. Oncol Rep 15: 65-71, 2006.

31. Chang ZG, Wei JM, Qin CF, Hao K, Tian XD, Xie K, Xie XH and Yang YM: Suppression of the epidermal growth factor receptor inhibits epithelial-mesenchymal transition in human pancreatic cancer PANC-1 cells. Dig Dis Sci 57: 1181-1189, 2012.
32. Rhodes LV, Tate CR, Segar HC, Burks HE, Phamduy TB, Hoang V, Elliott S, Gilliam D, Pounder FN, Anbalagan M, et al: Suppression of triple-negative breast cancer metastasis by pan-DAC inhibitor panobinostat via inhibition of ZEB family of EMT master regulators. Breast Cancer Res Treat 145: 593-604, 2014.

33. Gheldof A and Berx G: Cadherins and epithelial-to-mesenchymal transition. Prog Mol Biol Transl Sci 116: 317-336, 2013.

34. Miura N, Yano T, Shoji F, Kawano D, Takenaka T, Ito K, Morodomi Y, Yoshino I and Maehara Y: Clinicopathological significance of Sipl-associated epithelial mesenchymal transition in non-small cell lung cancer progression. Anticancer Res 29: 4099-4106, 2009.

35. Elloul S, Elstrand MB, Nesland JM, Tropé CG, Kvalheim G, Goldberg I, Reich R and Davidson B: Snail, Slug, and Smad-interacting protein 1 as novel parameters of disease aggressiveness in metastatic ovarian and breast carcinoma. Cancer 103: 1631-1643, 2005.

36. Rosivatz E, Becker I, Specht K, Fricke E, Luber B, Busch R, Höfler $\mathrm{H}$ and Becker K: Differential expression of the epithelial-mesenchymal transition regulators snail, SIP1, and twist in gastric cancer. Am J Pathol 161: 1881-1891, 2002.

37. Zhou C, Liu J, Tang Y, Zhu G, Zheng M, Jiang J, Yang J and Liang X: Coexpression of hypoxia-inducible factor- $2 \alpha$, TWIST2, and SIP1 may correlate with invasion and metastasis of salivary adenoid cystic carcinoma. J Oral Pathol Med 41: 424-431, 2012.

38. Sakamoto K, Imanishi Y, Tomita T, Shimoda M, Kameyama K, Shibata K, Sakai N, Ozawa H, Shigetomi S, Fujii R, et al: Overexpression of SIP1 and downregulation of E-cadherin predict delayed neck metastasis in stage I/II oral tongue squamous cell carcinoma after partial glossectomy. Ann Surg Oncol 19: 612-619, 2012.

39. Oztas E, Avci ME, Ozcan A, Sayan AE, Tulchinsky E and Yagci T: Novel monoclonal antibodies detect Smad-interacting protein 1 (SIP1) in the cytoplasm of human cells from multiple tumor tissue arrays. Exp Mol Pathol 89: 182-189, 2010.

40. Xia M, Hu M, Wang J, Xu Y, Chen X, Ma Y and Su L: Identification of the role of Smad interacting protein 1 (SIP1) in glioma. J Neurooncol 97: 225-232, 2010.

41. Liu S, Tetzlaff MT, Liu A, Liegl-Atzwanger B, Guo J and Xu X: Loss of microRNA-205 expression is associated with melanoma progression. Lab Invest 92: 1084-1096, 2012.

42. Dodge GR, Kovalszky I, McBride OW, Yi HF, Chu ML, Saitta B, Stokes DG and Iozzo RV: Human clathrin heavy chain (CLTC): Partial molecular cloning, expression, and mapping of the gene to human chromosome 17q11-qter. Genomics 11: 174-178, 1991.

43. Humphries AC, Dodding MP, Barry DJ, Collinson LM, Durkin $\mathrm{CH}$ and Way M: Clathrin potentiates vaccinia-induced actin polymerization to facilitate viral spread. Cell Host Microbe 12: 346-359, 2012

44. De Paepe P, Baens M, van Krieken H, Verhasselt B, Stul M, Simons A, Poppe B, Laureys G, Brons P, Vandenberghe P, et al: ALK activation by the CLTC-ALK fusion is a recurrent event in large B-cell lymphoma. Blood 102: 2638-2641, 2003.

45. Zhu Y, Qi C, Jain S, Rao MS and Reddy JK: Isolation and characterization of $\mathrm{PBP}$, a protein that interacts with peroxisome proliferator-activated receptor. J Biol Chem 272: 25500-25506, 1997.

46. Drané P, Barel M, Balbo M and Frade R: Identification of RB18A, a $205 \mathrm{kDa}$ new p53 regulatory protein which shares antigenic and functional properties with p53. Oncogene 15: 3013-3024, 1997.

47. Crawford SE, Qi C, Misra P, Stellmach V, Rao MS, Engel JD, Zhu Y and Reddy JK: Defects of the heart, eye, and megakaryocytes in peroxisome proliferator activator receptor-binding protein (PBP) null embryos implicate GATA family of transcription factors. J Biol Chem 277: 3585-3592, 2002. 